\title{
Penggerombolan Sekolah Menengah Atas Berdasarkan Nilai Ujian Nasional Di Kota Manado
}

\author{
Charles E. Mongi ${ }^{*}$, Chriestie E.J.C. Montolalu² \\ ${ }^{1,2}$ Program Studi Matematika, Fakultas Matematika dan Ilmu Pengetahuan Alam, \\ Universitas Sam Ratulangi Manado \\ *corresponding author email: charlesmongi@ unsrat.ac.id
}

\begin{abstract}
Abstrak
Pendidikan di Indonesia khususnya pada pendidikan menengah dan dasar diperhadapkan dengan berbagai permasalahan salah satunya pelaksanaan ujian nasional (UN). Penelitian ini merumuskan bagaimana membuat kelompok SMA di Kota Manado berdasarkan kemiripan karakteristik. Data yang digunakan dalam adalah data nilai ujian nasional SMA di Kota Manado tahun pelajaran 2014/2015. Peubah yang diamati yaitu nilai mata pelajaran berdasarkan program di SMA (program IPA, IPS, dan Bahasa). Pengamatan atau objek yaitu SMA negeri dan swasta di Kota Manado. Metode analisis yaitu analisis deskripsi dengan membuat tabel dan diagram untuk masing-masing peubah dan program. Analisis gerombol berhirarki dengan ukuran jarak Euclidian dan tahapan pembentukan gerombol menggunakan metode ward. Hasil yang didapat yaitu 3 gerombol/kelompok sekolah dengan kelompok pertama terdiri dari 13 sekolah kelompok kedua dengan 11 sekolah dan kelompok ketiga 6 sekolah.
\end{abstract}

Kata kunci : Penggerombolan, Sekolah Menengah Atas, Ujian Nasional

\section{Senior High School Clustering in Manado City Based on Nasional Exam Scores}

\begin{abstract}
Primary and secondary education in Indonesia was confronted with various problems, one of which is a national exam (UN). This study aims to formulate how to create a group of high schools in Manado based on similar characteristics. The data used is the national exam scores from high school in the city of Manado in the academic year 2014/2015. Variable measured is the value of subjects in high school based program, a program of science, social studies and language. Object of observation is public and private high school in Manado City. The analytical method used is descriptive analysis by creating tables and diagrams for each variables and programs. Ward method used for the analysis of hierarchical cluster with Euclidian distance measure and step in cluster formation. The results showed that 3 cluster / school groups with the first group consist of 13 schools, the second group with 11 schools, and a third group of 6 schools.
\end{abstract}

Keywords: Clustering, Senior High School, National exam

\section{Pendahuluan}

Pendidikan di Indonesia khususnya pada pendidikan menengah dan dasar diperhadapkan dengan berbagai permasalahan salah satunya pelaksanaan ujian nasional (UN). Terjadi pro dan kontra dalam pelaksanaan ujian nasional tersebut. Berdasarkan peraturan menteri pendidikan dan kebudayaan nomor 57 tahun 2015 bahwa penentuan kelulusan siswa tidak lagi mengacu pada nilai UN [1]. Kelulusan siswa ditentukan oleh sekolah masing-masing, yaitu jika telah menyelesaikan seluruh program pembelajaran, memperoleh nilai sikap minimal baik dan lulus ujian sekolah.

UN merupakan amanah dari undang-undang nomor 20 tahun 2003 tentang sistem pendidikan nasional yang bertujuan untuk mengukur pencapaian kompetensi lulusan pada mata pelajaran tertentu secara nasional dengan mengacu pada standar kompetensi lulusan [2,3]. Hasil dari UN akan digunakan untuk pemetaan mutu program pendidikan dan/atau sekolah, pertimbangan seleksi masuk 
jenjang pendidikan berikutnya, dan pertimbangan dalam pembinaan dan pemberian bantuan kepada sekolah dalam upaya meningkatkan mutu pendidikan [1].

Sekolah merupakan jalur pendidikan formal yang memiliki tiga jenjang salah satunya Sekolah Menengah Atas (SMA). SMA di Kota Manado berjumlah 46 sekolah dengan 9 sekolah berstatus negeri dan 37 sekolah berstatus swasta [4]. Dengan jumlah SMA yang sebanyak 46 membuat kebijakan pemerintah akan sulit untuk diterapkan dengan baik. Sehingga dengan dilakukan pengelompokkan SMA diharapakan akan membantu dalam penerapan kebijakan yang sesuai kebutuhan untuk SMA tersebut. salah satu metode untuk pengelompokkan adalah analisis gerombol (cluster analysis).

Penggerombolan merupakan salah satu metode untuk membuat kelompok suatu peubah (variable) atau pengamatan (object) yang memiliki kemiripan sifat. Analisis gerombol merupakan teknik peubah ganda yang mempunyai tujuan utama mengelompokkan objek-objek berdasarkan kemiripan karakteristik yang dimilikinya [5]. Dengan kata lain, keragaman dalam suatu gerombol minimum sedangkan keragaman antar gerombol maksimum.

Penelitian sebelumnya yang sudah dilakukan tentang penggerombolan provinsi di Indonesia berdasarkan indikator pendidikan SMA menggunakan metode ward dan fussy c-means [6]. Analisis gerombol tak berhirarki SMA/MA di Kota Kendari berdasarkan akreditasi sekolah menghasilkan 4 kelompok [7]. Analisis gerombol ensemble SMA/MA di Kota Padang menghasilkan 4 kelompok kemudian dilihat nilai akreditasinya [8].

Perumusan masalah dalam penelitian ini adalah bagaimana membuat kelompok SMA di Kota Manado yang memiliki kemiripan karakteristik. Karakteristik yang diambil yaitu nilai UN berdasarkan mata pelajaran yang sesuai dengan program yang ada di sekolah. Program (IPA, IPS, Bahasa) di suatu sekolah berbeda-beda, ada yang hanya memiliki program IPA dan IPS saja, ada yang memiliki Program IPS dan Bahasa saja ada yang memiliki ketiganya. Tujuan penelitian ini adalah menggerombolkan SMA di Kota Manado berdasarkan nilai ujian nasional menggunakan analisis gerombol berhirarki.

\section{Pendidikan}

Pendidikan adalah usaha sadar dan terencana untuk mewujudkan suasana belajar dan proses pembelajaran agar peserta didik secara aktif mengembangkan potensi dirinya untuk memiliki kekuatan spiritual keagamaan, pengendalian diri, kepribadian, kecerdasan, akhlak mulia, serta keterampilan yang diperlukan dirinya, masyarakat, bangsa dan negara. Jalur Pendidikan terdiri atas pendidikan formal, nonfomal dan informal. Jenjang pendidikan formal terdiri atas pendidikan dasar, pendidikan menengah dan pendidikan tinggi [3].

\section{Analisis Gerombol}

Analisis gerombol secara sederhana tidak memerlukan asumsi tentang jumlah kelompok atau struktur kelompok [9]. Pengelompokkan hanya dilakukan atas dasar kedekatan (similarities) atau jarak (dissimilarities). Untuk mengelompokan observasi ke dalam kelompok, banyak teknik dimulai dengan kedekatan antara semua pasangan pengamatan [10]. Dalam banyak kasus kesamaan didasarkan pada beberapa ukuran jarak. Analisis gerombol juga telah disebut sebagai klasifikasi, pengenalan pola (specifically, unsupervised learning), dan taksonomi numerik. Dua pendekatan umum untuk mengelompokkan vektor observasi yaitu hirarki clustering dan partisi.

Ukuran jarak yang sering digunakan yaitu jarak Euclidian, minkowski metric, jarak city block, jarak Euclidian kuadrat. Cara mencari jarak Euclidian antara dua vector $x=\left(x_{1}, x_{2}, \ldots x_{\mathrm{p}}\right)^{\prime}$ dan $y=\left(y_{1}, y_{2}, \ldots y_{\mathrm{p}}\right)^{\prime}$, didefinisikan sebagai

$$
d(x, y)=\sqrt{(x-y)^{\prime}(x-y)}=\sqrt{\sum_{j=1}^{p}\left(x_{j}-y_{j}\right)^{2}},[10] .
$$

Penggerombolan berhirarki digunakan jika jumlah gerombol belum diketahui. Terdapat dua cara pembentukan gerombol yaitu agglomerative dan divisive. Tahapan pembentukan gerombol ada beberapa metode antara lain single linkage, complete linkage, average linkage, metode centroid, metode median dan metode ward. Cara mencari dengan metode ward adalah:

$$
\mathrm{D}_{\mathrm{AB}}=\mathrm{SSE}_{\mathrm{AB}}-\left(\mathrm{SSE}_{\mathrm{A}}+\mathrm{SSE}_{\mathrm{B}}\right) \text {, }
$$




$$
\begin{aligned}
& \text { dengan } \operatorname{SSE}_{\mathrm{A}}=\sum_{i=1}^{n A}\left(y_{i}-\bar{y}_{A}\right)^{\prime}\left(y_{i}-\bar{y}_{A}\right) \text {, } \\
& \mathrm{SSE}_{\mathrm{B}}=\sum_{i=1}^{n B}\left(y_{i}-\bar{y}_{B}\right)^{\prime}\left(y_{i}-\bar{y}_{B}\right), \\
& \operatorname{SSE}_{\mathrm{AB}}=\sum_{i=1}^{n A B}\left(y_{i}-\bar{y}_{A B}\right)^{\prime}\left(y_{i}-\bar{y}_{A B}\right) \text {, } \\
& \bar{y}_{A B}=\left(\mathrm{n}_{\mathrm{A}} \bar{y}_{A}+\mathrm{n}_{\mathrm{B}} \bar{y}_{B}\right) /\left(\mathrm{n}_{\mathrm{A}}+\mathrm{n}_{\mathrm{B}}\right),[10] .
\end{aligned}
$$

\section{Metode Penelitian}

\subsection{Sumber Data}

Data yang digunakan dalam penelitian ini adalah data nilai ujian nasional SMA di Kota Manado tahun pelajaran 2014/2015. Peubah yang diamati yaitu nilai mata pelajaran berdasarkan program di SMA (program IPA, IPS, dan Bahasa). SMA yang dipakai adalah SMA negeri dan swasta.

\subsection{Metode Analisis}

a. Analisis Deskripsi

Analisis deskripsi dengan membuat tabel rata-rata nilai dan diagram batang setiap sekolah berdasarkan program di SMA.

b. Analisis Gerombol

Analisis gerombol dengan membuat dendogram berdasarkan program SMA. Teknik analisis gerombol yang digunakan dalam penelitian ini adalah teknik berhirarki agglomerative dengan langkah-langkah sebagai berikut:

a. Membuat matriks jarak dengan jarak antar gerombol menggunakan jarak euclidean.

b. Dua objek dengan jarak terpendek digabungkan dalam satu gerombol baru (objek adalah sekolah).

c. Memperbaharui matriks jarak antar gerombol dengan menggunakan metode ward.

d. Mengulangi langkah $b$ dan $c$ sampai terbentuk satu gerombol yang beranggotakan semua objek.

e. Melakukan pemotongan dendogram dengan melihat pertambahan jarak terbesar [11].

\section{Hasil dan Pembahasan}

Nilai UN untuk program IPA seperti dalam Tabel 1 terdapat 30 sekolah baik yang berstatus negeri dan swasta. Mata pelajaran untuk program IPA yaitu Bahasa Indonesia, Bahasa Inggris, Matematika, Fisika, Kimia dan Biologi.

Tabel 1. Nilai UN SMA Program IPA

\begin{tabular}{|l|r|r|r|r|r|r|}
\hline \multicolumn{1}{|c|}{ Sekolah } & B.Indonesia & B.Inggris & Matematika & Fisika & Kimia & Biologi \\
\hline $\begin{array}{l}\text { SMA KATOLIK REX MUNDI } \\
\text { MANADO }\end{array}$ & 89.71 & 90.72 & 79.33 & 91.08 & 78.81 & 77.43 \\
\hline $\begin{array}{l}\text { SMA KATOLIK DON BOSCO } \\
\text { MANADO }\end{array}$ & 84.55 & 79.21 & 81.58 & 81.88 & 80.9 & 73.55 \\
\hline SMA NEGERI 1 MANADO & 71.02 & 85.7 & 76.15 & 85.15 & 78.55 & 71.04 \\
\hline SMA NEGERI 9 MANADO & 74.92 & 84.37 & 74.41 & 88.63 & 78.21 & 66.95 \\
\hline SMA PIONEER MANADO & 71 & 90.21 & 70.55 & 90.78 & 69.22 & 74.07 \\
\hline SMA NEGERI 8 MANADO & 69.7 & 78.22 & 81.93 & 90.87 & 72.94 & 70.88 \\
\hline SMA NEGERI 2 MANADO & 78.82 & 69.19 & 80.46 & 81.9 & 68.22 & 80.49 \\
\hline SMA NEGERI 7 MANADO & 79.63 & 71.22 & 81.72 & 86.42 & 61.46 & 67.91 \\
\hline $\begin{array}{l}\text { SMA KRISTEN YPKM } \\
\text { MANADO }\end{array}$ & 77.52 & 80.43 & 67.78 & 80.53 & 75.14 & 62.25 \\
\hline $\begin{array}{l}\text { SMA KRISTEN EBEN HAEZAR } \\
\text { MANADO }\end{array}$ & 75 & 78.63 & 67.31 & 78.69 & 69.02 & 65.82 \\
\hline SMA NEGERI 4 MANADO & 63.1 & 75.15 & 72.39 & 80.27 & 72.07 & 68.83 \\
\hline
\end{tabular}




\begin{tabular}{|l|r|r|r|r|r|r|}
\hline \multicolumn{1}{|c|}{ Sekolah } & B.Indonesia & B.Inggris & \multicolumn{1}{c|}{ Matematika } & Fisika & Kimia & Biologi \\
\hline SMA EL SHADDAI MANADO & 60.02 & 78.15 & 69.92 & 84.63 & 67.2 & 66.93 \\
\hline SMA NEGERI 3 MANADO & 63.77 & 68.41 & 66.8 & 80.58 & 71.56 & 69.73 \\
\hline $\begin{array}{l}\text { SMA KRISTEN IRENE } \\
\text { MANADO }\end{array}$ & 76.07 & 82.45 & 72.98 & 87.71 & 30.12 & 68.33 \\
\hline $\begin{array}{l}\text { SMA KRISTEN AGAPE } \\
\text { MANADO }\end{array}$ & 59.97 & 73.81 & 76.04 & 86.05 & 41.88 & 66.02 \\
\hline SMA SPEKTRUM MANADO & 62.27 & 76.52 & 62.69 & 83.26 & 48.08 & 58.33 \\
\hline SMAS DIAN HARAPAN & 78.39 & 69.87 & 61.07 & 59.97 & 61.07 & 56.79 \\
\hline $\begin{array}{l}\text { SMA KRISTEN ELFATAH } \\
\text { MANADO }\end{array}$ & 49.49 & 76.2 & 59.44 & 74.08 & 62.78 & 60.84 \\
\hline $\begin{array}{l}\text { SMA KATOLIK IGNATIUS } \\
\text { MANADO }\end{array}$ & 67 & 76.66 & 52.43 & 69.73 & 53.14 & 61.59 \\
\hline $\begin{array}{l}\text { SMA KATOLIK AQUINO } \\
\text { MANADO }\end{array}$ & 62.97 & 69.11 & 57.77 & 70.57 & 50.87 & 66.18 \\
\hline SMA NEGERI 6 MANADO & 60.72 & 63.06 & 63.81 & 73.65 & 33.69 & 67.22 \\
\hline $\begin{array}{l}\text { SMA IMAM BONJOL } \\
\text { MANADO }\end{array}$ & 57.72 & 66.6 & 33.75 & 83.49 & 25.14 & 58.56 \\
\hline SMA ANTHONIUS MANADO & 56.5 & 54.52 & 46.5 & 87.86 & 24 & 49.44 \\
\hline SMA KARSIA MANADO & 44.18 & 61.91 & 25.54 & 80.65 & 25.89 & 52.91 \\
\hline $\begin{array}{l}\text { SMA ADVENT KLABAT } \\
\text { MANADO }\end{array}$ & 63.82 & 48.71 & 25.91 & 35.78 & 24.89 & 34.2 \\
\hline $\begin{array}{l}\text { SMA MUHAMMADYAH } \\
\text { MANADO }\end{array}$ & 59.53 & 34.32 & 23.33 & 41.28 & 25.69 & 32.24 \\
\hline $\begin{array}{l}\text { SMA KATOLIK LAURENTIUS } \\
\text { MANADO }\end{array}$ & 56.98 & 51.99 & 23.44 & 22.83 & 21.88 & 28.79 \\
\hline SMA NEGERI 10 MANADO & 63.85 & 42.4 & 23.13 & 20.88 & 25 & 29.53 \\
\hline SMA PERTIWI MANADO & 44.94 & 45.61 & 22.14 & 25.59 & 22.86 & 25.79 \\
\hline SMA BUDI UTOMO MANADO & 37.68 & 23.4 & 17.78 & 19.72 & 23.61 & 22.43 \\
\hline
\end{tabular}

Data nilai UN kemudian dibuat kelompok menggunakan analisis gerombol yang hasilnya terdapat dalam Gambar 1. Dari hasil penggabungan gerombol dipilih 3 gerombol karena perubahan jarak terbesar pertama kali terjadi pada gerombol ketiga. Selanjutnya dibuat dendogram seperti dalam Gambar 2 untuk memperlihatkan proses penggabungan setiap gerombol yang ada.

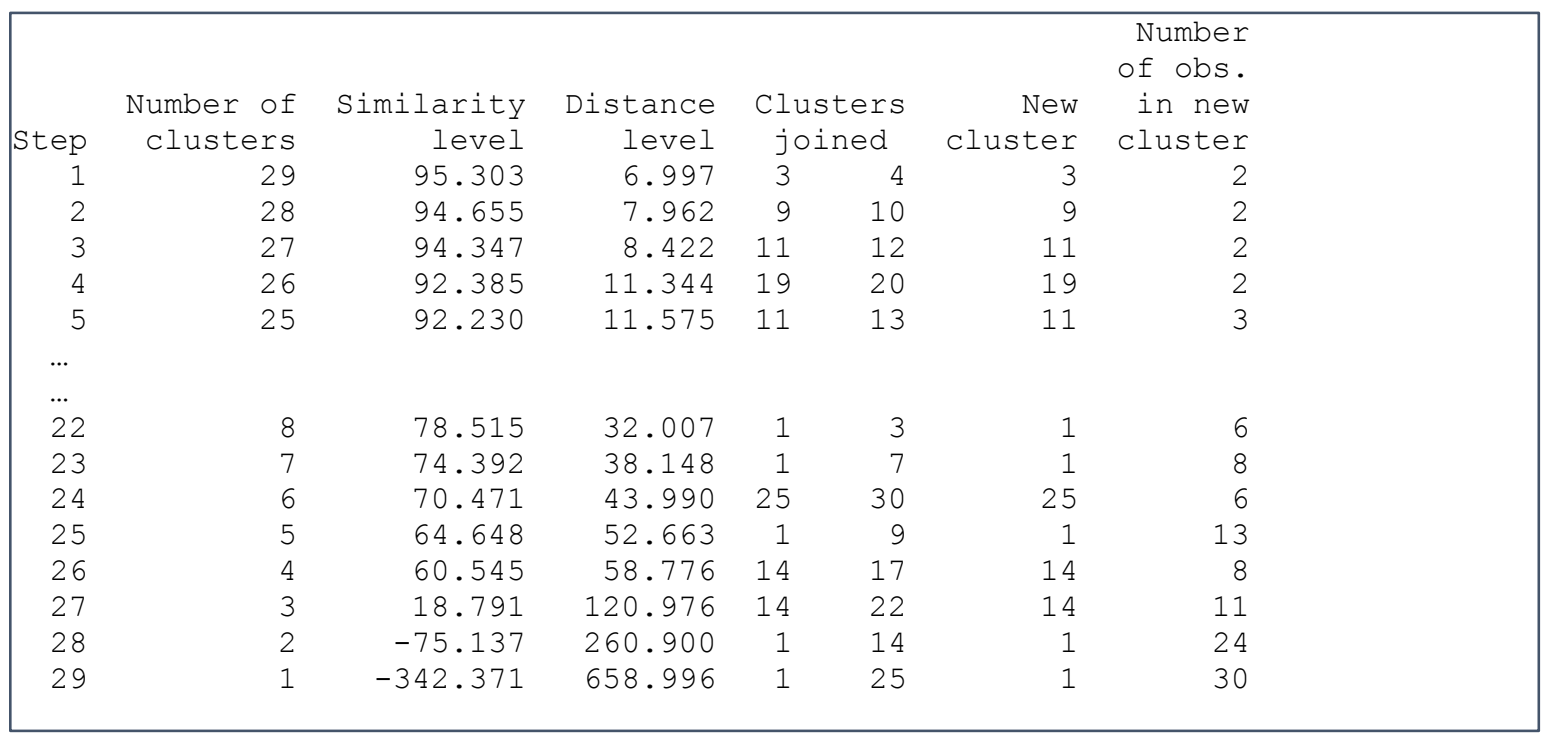

Gambar 1. Tahapan Pembentukan Gerombol Menggunakan Metode Ward 
Hasil 3 gerombol untuk setiap sekolah terdapat dalam Tabel 2, dalam gerombol pertama terdapat 13 sekolah, gerombol kedua 11 sekolah dan 6 sekolah dalam gerombol ketiga. Jika dilihat dari nilai rata-rata setiap gerombol maka gerombol pertama memiliki rata-rata nilai yang tinggi, gerombol 2 memiliki rata-rata nilai yang sedang dan gerombol 3 memiliki rata-rata nilai yang rendah dapat dilihat dalam Gambar 3.

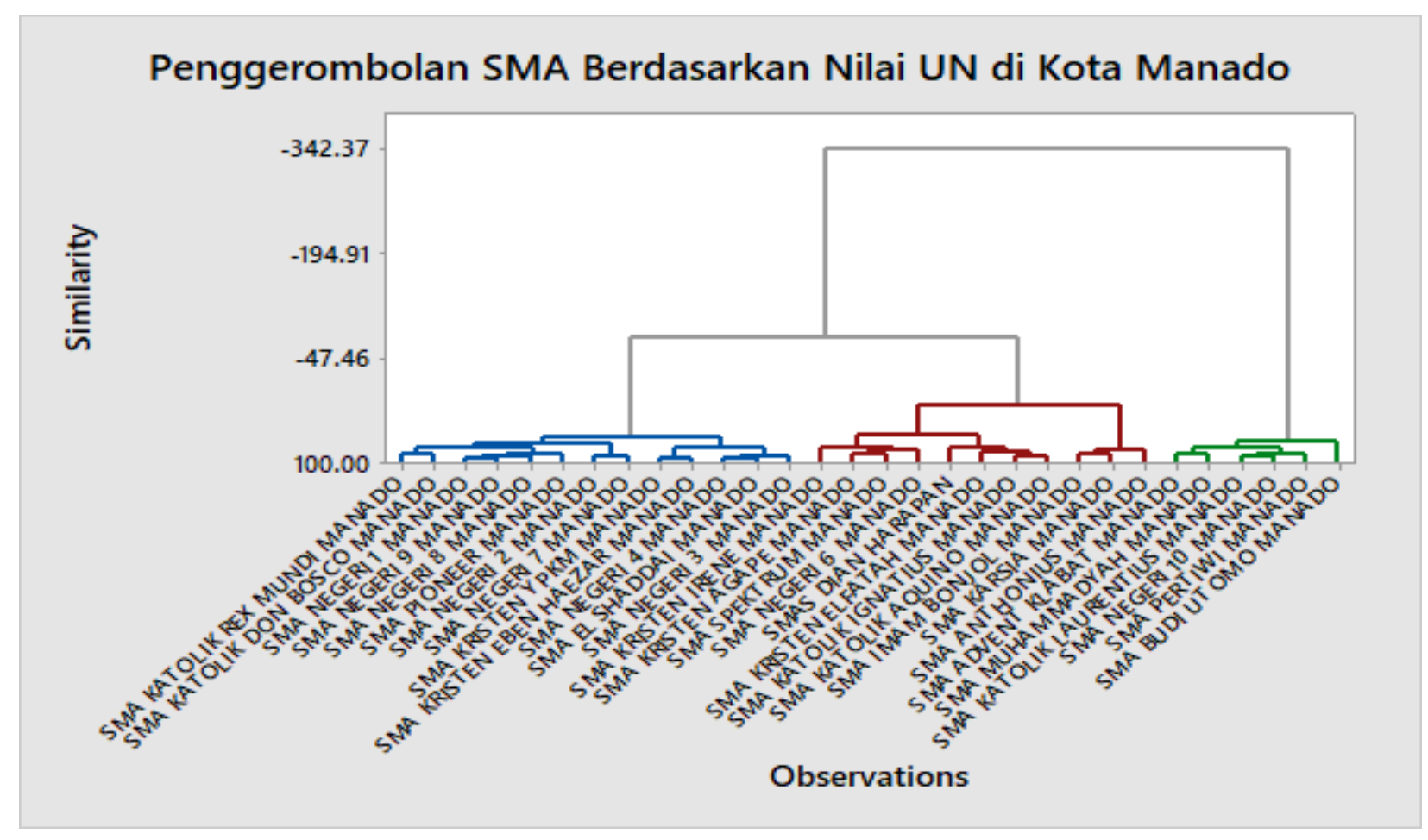

Gambar 2. Dendogram Menggunakan Metode Ward

Tabel 2. Sekolah Hasil Penggerombolan

\begin{tabular}{|l|l|l|}
\hline \multicolumn{1}{|c|}{1} & \multicolumn{1}{|c|}{2} \\
\hline $\begin{array}{l}\text { SMA KATOLIK REX MUNDI } \\
\text { MANADO }\end{array}$ & $\begin{array}{l}\text { SMA KRISTEN IRENE } \\
\text { MANADO }\end{array}$ & $\begin{array}{l}\text { SMA ADVENT KLABAT } \\
\text { MANADO }\end{array}$ \\
\hline $\begin{array}{l}\text { SMA KATOLIK DON BOSCO } \\
\text { MANADO }\end{array}$ & $\begin{array}{l}\text { SMA KRISTEN AGAPE } \\
\text { MANADO }\end{array}$ & $\begin{array}{l}\text { SMA MUHAMMADYAH } \\
\text { MANADO }\end{array}$ \\
\hline SMA NEGERI 1 MANADO & SMA SPEKTRUM MANADO & $\begin{array}{l}\text { SMA KATOLIK } \\
\text { LAURENTIUS MANADO }\end{array}$ \\
\hline SMA NEGERI 9 MANADO & SMAS DIAN HARAPAN & SMA NEGERI 10 MANADO \\
\hline SMA PIONEER MANADO & $\begin{array}{l}\text { SMA KRISTEN ELFATAH } \\
\text { MANADO }\end{array}$ & SMA PERTIWI MANADO \\
\hline SMA NEGERI 8 MANADO & $\begin{array}{l}\text { SMA KATOLIK IGNATIUS } \\
\text { MANADO }\end{array}$ & $\begin{array}{l}\text { SMA BUDI UTOMO } \\
\text { MANADO }\end{array}$ \\
\hline SMA NEGERI 2 MANADO & $\begin{array}{l}\text { SMA KATOLIK AQUINO } \\
\text { MANADO }\end{array}$ & \\
\hline SMA NEGERI 7 MANADO & SMA NEGERI 6 MANADO & \\
\hline $\begin{array}{l}\text { SMA KRISTEN YPKM } \\
\text { MANADO }\end{array}$ & $\begin{array}{l}\text { SMA IMAM BONJOL } \\
\text { MANADO }\end{array}$ & \\
\hline $\begin{array}{l}\text { SMA KRISTEN EBEN HAEZAR } \\
\text { MANADO }\end{array}$ & SMA ANTHONIUS MANADO & \\
\hline SMA NEGERI 4 MANADO & SMA KARSIA MANADO & \\
\hline SMA EL SHADDAI MANADO & \multicolumn{2}{|l}{} \\
\hline SMA NEGERI 3 MANADO & \multicolumn{2}{|l}{} \\
\hline
\end{tabular}




\begin{tabular}{|lrrr|}
\hline Variable & Cluster1 & Cluster2 & Cluster3 \\
Bah Ind & 73.7508 & 61.3891 & 54.4667 \\
Bah Ing & 79.2008 & 70.0645 & 41.0717 \\
Mat & 74.6408 & 55.6382 & 22.6217 \\
Fis & 84.7238 & 77.9109 & 27.6800 \\
Kim & 72.5615 & 41.5145 & 23.9883 \\
Bio & 70.4523 & 60.5645 & 28.8300 \\
\hline
\end{tabular}

Gambar 3. Nilai Rata-rata Setiap Gerombol

\section{Kesimpulan dan Saran}

Berdasarkan hasil yang didapat yaitu 3 gerombol/kelompok sekolah dengan kelompok pertama terdiri dari 13 sekolah kelompok kedua dengan 11 sekolah dan kelompok ketiga 6 sekolah.

\section{Ucapan Terima Kasih}

Penulis mengucapkan terima kasih kepada Direktorat Riset dan Pengabdian pada Masyarakat (DRPM), Kementerian Riset Teknologi dan Pendidikan Tinggi Dirjen melalui Lembaga Penelitian dan Pengabdian kepada Masyarakat (LPPM) UNSRAT yang telah mendanai penelitian ini pada skim Penelitian Dosen Pemula (PDP) tahun 2017.

\section{Daftar Pustaka}

[1] Kemendikbud. 2015. Peraturan Menteri Pendidikan dan Kebudayaan Republik Indonesia Nomor 57 Tahun 2015 Tentang Penilaian Hasil Belajar Oleh Pemerintah Melalui Ujian Nasional, Dan Penilaian Hasil Belajar Oleh Satuan Pendidikan Melalui Ujian Sekolah/Madrasah/Pendidikan Kesetaraan Pada SMP/MTs Atau Yang Sederajat Dan SMA/MA/SMK Atau Yang Sederajat.

[2] Kemendikbud. 2016. Web Pelaksanaan Ujian Nasional. [Terhubung berkala]. http://www.un.kemendikbud.go.id [24 Mei 2016]

[3] Pemerintah RI. 2003. Undang-Undang Republik Indonesia Nomor 20 Tahun 2003 Tentang Sistem Pendidikan Nasional.

[4] BPS Manado. 2014. Manado Dalam Angka 2014. Badan Pusat Statistik Kota Manado. Manado.

[5] Mattjik A.A, I.M. Sumertajaya. 2011. Sidik Peubah Ganda. Bogor: Departemen Statistika FMIPA-IPB.

[6] Mulyanto A. 2010. Penggerombolan Provinsi di Indonesia Berdasarkan Indicator Pendidikan Sekolah Lanjutan Atas Menggunakan Metode Ward dan Metode Fuzzy C-Means [Skripsi]. Bogor: Institut Pertanian Bogor.

[7] Sarlia D. 2014. Analisis Gerombol Tak Berhirarki Untuk Mengelompokkan SMA/MA di Kota Kendari Berdasarkan Komponen Akreditasi Sekolah [Skripsi]. Kendari: Universitas Haluoleo.

[8] Fittri R.Y. 2014. Analisis Gerombol Menggunakan Metode Cluster Ensemble [Skripsi]. Padang: Universitas Andalas.

[9] Johnson R.A, D.W. Wichern. 2007. Applied Multivariate Statistical Analysis $6^{\text {th }}$ edition. London: Prentice-Hall.

[10] Rencher A.C, W.F. Christensen. 2012. Methods of Multivariate Analysis $3^{\text {rd }}$ edition. New York: John Wiley \& Sons, Inc.

[11] Mongi C.E. 2014. Penggerombolan dan Pemetaan Kabupaten/Kota di Provinsi Jawa Barat Berdasarkan Nilai Ujian Nasional SMA dan Akreditasi Sekolah [Tesis]. Bogor: Institut Pertanian Bogor. 